\title{
Study on Preparation of Nitrogen-Doped Hierarchically Porous and High-Performance Carbon Materials from Seaweed Biomass
}

\author{
Kaihan Xie $^{1}$, Yamin $\mathrm{Hu}^{1,}$, Stephen Afonaa-Mensah ${ }^{2}$, Chuan Yuan ${ }^{1}$, Bin $\mathrm{Cao}^{1}$, Shuang Wang ${ }^{1, *}$ and \\ Qian Wang ${ }^{1}$
}

${ }^{1}$ School of Energy and Power Engineering, Jiangsu University, Zhenjiang, China

${ }^{2}$ Takoradi Technical University, Takoradi, Ghana

${ }^{*}$ Corresponding Authors: Shuang Wang. Email: alexjuven@ujs.edu.cn; Yamin Hu. Email: ymin@ujs.edu.cn

Received: 16 June 2021 Accepted: 04 August 2021

\begin{abstract}
Use Enteromorpha clathrate as a carbon and nitrogen precursor could obtain the N-doped porous carbon materials by two-step pyrolysis. In this paper, the exogenous nitrogen (urea, melamine) and activating agents (KOH, $\mathrm{ZnCl}_{2}$ ) were employed for the production of higher-performance carbon materials from seaweed biomass. SEM, BET, FTIR, XRD, XPS, Raman and ultimate analyses were carried out to investigate the morpho-structural and elemental peculiarities of the carbonaceous materials. Moreover, cyclic voltammetry (CV), galvanostatic chargedischarge (GCD) and cyclic charge-discharge tests were carried out to examine the electrochemical properties of the samples. The results showed that electrochemical performance of the carbonaceous materials improved by adding the appropriate nitrogen sources. This improvement was observed under either condition, when the nitrogen source and activating agent were melamine and $\mathrm{ZnCl}_{2}$ or urea and $\mathrm{KOH}$, respectively. Specifically, under the condition with $\mathrm{KOH}$ as the activator, the nitrogen content of carbon material without exogenous nitrogen was initially $1.46 \%$. After the addition of urea or melamine, the nitrogen content increased to $4.86 \%$ and $6.18 \%$, respectively. Under the condition with $\mathrm{ZnCl}_{2}$ as the activator, and without exogenous nitrogen, the nitrogen content of carbon materials was initially 3.75\%. However, after adding urea or melamine, the nitrogen content increased to $12.11 \%$ and $14.76 \%$, respectively. The carbonaceous materials (prepared from urea/KOH and melamine $/ \mathrm{ZnCl}_{2}$ ) showed excellent gravimetric capacitances of 172 and $151.5 \mathrm{~F} / \mathrm{g}$ at $1 \mathrm{~A} / \mathrm{g}$. Moreover, at a current density of $5 \mathrm{~A} / \mathrm{g}$, their specific capacitance retention rate reached $78.3 \%$ and $82.6 \%$ respectively after 1000 cycles.
\end{abstract}

\section{KEYWORDS}

Exogenous nitrogen incorporation; N-doped porous carbon; two-steps pyrolysis; enteromorpha clathrate

\section{Introduction}

With the rapid development of the world's economy, the $21^{\text {st }}$ century is facing a global challenge of fast depleting energy resources. At the same time, the overuse of traditional fossil fuels is causing series of environmental problems which is adversely impacting the sustainable development of the world economy. Therefore, developing renewable energy into high-quality energy sources to reduce the overuse of fossil fuels and increasing $\mathrm{CO}_{2}$ sequestration efficiency are important for the sustainable development of the economy and society [1-3]. However, renewable energy sources are generally characterized by uneven 
distribution in time and space, and are greatly affected by the environment and climate. Hence, the use of renewable energy sources gives rise to the need for energy storage devices to mitigate the existing challenges of discontinuity and instability in renewable energy sources. In this regard, a supercapacitor is a new type of energy storage device with many advantages such as high power density, long cycle life, wide working temperature limit, environmental protection, safety, capability to store and deliver energy at relatively high rates, among others [4].

Based on the energy storage mechanism, supercapacitors can be categorized into electric double-layer capacitors and pseudocapacitors [5]. The electric double-layer capacitor collects electric charge through the interface double layer formed by electrode and electrolyte to realize the function of energy storage [6]. Since the adsorption of the physical process is the only thing in the double-layer capacitor, it can be inferred that the double-layer capacitors have the advantages of excellent cycle stability and high charge-discharge coulomb efficiency [7]. The electric charge produced by the electric double layer is similar to that of the dielectric in the traditional capacitor under the electric field. However, as the distance between the tight charge layers is much smaller than that of the ordinary capacitor charge layers, electric double-layer capacitors have larger capacitance [8]. Pseudocapacitance is known as Faraday quasi-capacitance. Faradaic reactions are present in pseudocapacitors, which is the essential difference between pseudocapacitors and electric double-layer capacitors. The Faradaic reaction occurs in the presence of an underpotential deposition, desorption, adsorption, or redox reaction of electroactive substances on the electrode surface or inside the electrode. Since pseudocapacitor mainly depends on chemical reaction to store energy, the capacity of the pseudocapacitor could be 10-100 times that of the electric double-layer capacitor with the same electrode surface area $[7,9,10]$. The redox reaction of the Faraday capacitor is very fast, the energy level state of electrode material changes constantly during the charge-discharge process. Therefore, the voltage of Faraday capacitor is proportional to the charge-discharge quantity, that is, in the constant current charge-discharge process, the voltage changes linearly with the charge-discharge time [11,12].

Carbon-based materials, metal oxides, conductive polymers, and other structures are commonly used in supercapacitor electrode materials. Among them, carbonaceous materials have the advantages of high conductivity, long cycle life, stable physical and chemical properties, broad applicability, and controllable microstructure [5]. However, the major drawbacks of carbon materials are that the contribution to the electric double-layer capacitance is dominant, the redox reaction does not occur in the process of electrochemical storage, and the contribution of pseudocapacitance is small [13]. In addition, there are fewer functional groups on the surface of carbon materials, which reduce the wettability of the surface of carbon materials. This is not conducive to the full utilization of the pore structure of carbon materials and consequently reduces its electrochemical performance [14].

Many scholars have investigated the preparation of supercapacitors using biomass as a carbon source. Han et al. [11] screened the optimal activation conditions of corncob-based activated carbon by orthogonal test. In the study, the authors prepared electrode materials with specific surface area of $1683.42 \mathrm{~m}^{2} / \mathrm{g}$ and specific capacitance attenuation of $10 \%$ after 10000 constant current charge and discharge cycles. The specific capacitance was $138.00 \mathrm{~F} / \mathrm{g}$ at $1 \mathrm{~A} / \mathrm{g}$. Du et al. [15] prepared activated carbon (AC) $-\mathrm{Fe}_{3} \mathrm{O}_{4}$ nanoparticles asymmetric supercapacitor cells, by the microwave method, with specific surface area of $1197 \mathrm{~m}^{2} / \mathrm{g}$, carbon content of $82 \%$ and specific capacitance of $37.9 \mathrm{~F} / \mathrm{g}$. Jiang et al. [16] obtained hierarchical ordered macroporous biochar block by pyrolysis and carbonization of red cedar wood, with specific surface area of $317 \mathrm{~m}^{2} / \mathrm{g}$, carbon content of $98 \%$, and specific capacitance of $115 \mathrm{~F} / \mathrm{g}$. Considering these results, it can be seen that thermochemical methods are among the essential pathways to prepare carbon electrode materials for supercapacitors.

Shi et al. [10,17] studied the relationship between specific surface area, pore volume, pore size, pore structure and specific capacitance, and found that the pore size distribution has a certain influence on the 
charge-discharge performance. The larger the pore size, the faster the electrochemical adsorption speed, which can meet the requirements of rapid charge and discharge, and is suitable for the preparation of high-power supercapacitors. Micropores can greatly increase the specific surface area of carbon materials. When the pore size matches the electrolyte ion or its double size, it is most favorable for the formation of the electric double layer, and has a greater impact on the contrast capacitance [18].

However, the pore structures of carbon materials prepared by the thermochemical method are inferior, so the materials need to be activated to improve the pore structure and specific surface area. $\mathrm{KOH}, \mathrm{ZnCl}_{2}$, and $\mathrm{K}_{2} \mathrm{CO}_{3}$ are commonly used as activators. The activation mechanism of $\mathrm{KOH}$ is based on the direct reaction with carbon to release $\mathrm{CO}$ and $\mathrm{H}_{2}$. The as-escaping gaseous phase induces porous structures in the carbonaceous materials. The high temperature reduced potassium is embedded into the structure of the carbon-based lattice, resulting in the expansion of the structure, thus, increasing the specific surface area and pore volume of electrode materials [19]. The activation mechanism of $\mathrm{ZnCl}_{2}$ is mainly based on catalytic dehydration at high temperatures acting as a skeleton during carbonization. Also, the activated carbon prepared by $\mathrm{ZnCl}_{2}$ has rich internal pore structure and high specific surface area [20].

However, the as-obtained materials often have low capacitance, which could not meet the requirements for efficient applicability as supercapacitors. Doping heteroatoms, such as N, O, P, B, or S with high polarity, can improve the electrochemical performance of pseudocapacitors [21]. The electronegativity of nitrogen is greater than that of carbon, but the atomic radius is almost the same. Nitrogen can disturb the carbon atom array and produce more defect sites. Moreover, nitrogen doping can affect the wettability of the materials and maximize the electroactive surface area [22,23]. Due to the strong electronegativity of nitrogen atoms, electrons are enriched around them, which makes adjacent carbon atoms with positive charges. This is conducive for the adsorption of oxygen molecules and further promotes the process of oxygen reduction reaction. The addition of nitrogen can promote the formation of graphite nitrogen and pyridine nitrogen, which can enhance the oxygen adsorption and oxygen reduction on the active sites, and accelerate electron transfer [21,24]. At the same time, nitrogen atoms have lone pair electrons. It can not only increase the electron density of carbon materials but also increase the maximum occupied orbital energy of $\mathrm{SP}^{2}$ hybrid carbon, thus improving the catalytic activity of carbon materials for oxygen reduction [25]. Nitrogen doping can also form nitrogen-containing functional groups such as $\mathrm{C}=\mathrm{N}$ in carbon materials which can react with electrolyte to improve the pseudo capacitance of carbon materials [26].

Huang et al. [27] used soybean shells as carbon and nitrogen sources and calcination, $\mathrm{KOH}$ activation method to prepare biomass porous nitrogen doped graphene. This material showed a high surface area $\left(1152 \mathrm{~m}^{2} \mathrm{~g}^{-1}\right)$, and exhibited unique properties of mesoporosity and high pyridine-nitrogen content. Zhou et al. [28] used a novel self-template strategy to develop synthesize nitrogen doped porous graphenes by using porous biomass with an abundant plate-like structure as a template, fully coupled with $\mathrm{KOH}$ activation, and followed by nitrogen doping by $\mathrm{NH}_{3}$ injection. This material showed an ultrahigh surface area (approximately to $1969 \mathrm{~m}^{2} \mathrm{~g}^{-1}$ ), high electron conductivity of the graphene structure and efficient nitrogen content.

In recent years, the thermochemical transformation of seaweed to obtain high added value products with more application potential than conventional raw materials has become the focus of industry [29]. Compared with woody biomass, algae have higher light absorption efficiency, faster growth, and higher biomass yield [30]. In terms of energy conversion and utilization, terrestrial biomass is mainly composed of lignin, cellulose, and other refractory components, which have high thermal stability, decreasing the costefficiency. However, algae contain more pyrolytic chemicals, such as lipids, soluble polysaccharides, and proteins, which makes them more prone to pyrolysis and the release of volatiles [31,32].

Li et al. [33] found that the specific surface area of carbonaceous materials first increased and then decreased with pyrolysis temperature. This is because at the initial stage of pyrolysis, the volatile gas 
escapes from the inner structures of the sample, and the activator forms porous carbon materials. However, with the increase of the temperature, the etching effect of the activator and the volatile gas is further enhanced. This process destroys the original microporous structure and turn them into macropores, consequently, reducing the specific surface area of the carbon materials. Therefore, most of the volatiles should be removed before the carbon materials are activated [33]. The two-step pyrolysis method can effectively solve this problem. The raw material used in this study is Enteromorpha clathrate. Enteromorpha clathrate is a species of green algae, which grows rapidly and is widely distributed in various waters. It was already found that $164.9-512.7^{\circ} \mathrm{C}$ is the main analysis range of the volatile matter in the pyrolysis process [34]. In the process of pyrolysis, staying at $550^{\circ} \mathrm{C}$ for $60 \mathrm{~min}$, then adding activator is beneficial to the full precipitation of volatile matter. This process can prevent the destruction of microporous structure, improve the specific surface area and pore structure of carbon materials, and subsequently, improve their electrochemical performance.

In this study, nitrogen-doped carbon materials were synthesized by a two-step pyrolysis method. Enteromorpha clathrate was used as a nitrogen source and carbon source, while melamine or urea was used as exogenous nitrogen agent. The effects of different nitrogen sources (melamine, urea) and activating agents $\left(\mathrm{KOH} / \mathrm{ZnCl}_{2}\right)$ on the properties of carbon materials were systematically studied.

\section{Experimental}

\subsection{Raw Materials}

Enteromorpha clathrate was selected as the raw material for pyrolysis. Firstly, the algae were dried in the air, then cut into sections, crushed, and sieved to $80 \mathrm{mesh}$. Then, it was dried in a drying oven at $105^{\circ} \mathrm{C}$ for $24 \mathrm{~h}$.

Enteromorpha clathrata was obtained from the Xiangshan Port of Zhejiang Province located on the south coast of China. Melamine, urea, $\mathrm{HCl}, \mathrm{KOH}, \mathrm{ZnCl}_{2}$, carbon black, polytetrafluoroethylene and 1methyl-2-pyrrolidone were supplied by Sinopharm Chemical Reagent Co., Ltd., Shanghai, China. $\mathrm{N}_{2}$ was supplied by Danyang Hongshun gas business department.

\subsection{Methods}

\subsubsection{Preparation of Activated Carbon}

The as-dried Enteromorpha clathrate and melamine (urea) were mixed in the ratio of 1:1, and the mixture was put into a tubular furnace. The mixture was heated to $550^{\circ} \mathrm{C}$ at a heating rate of $5{ }^{\circ} \mathrm{C} / \mathrm{min}$ and kept for $60 \mathrm{~min}$, using nitrogen atmosphere. After cooling, $\mathrm{KOH}$ or $\mathrm{ZnCl}_{2}$ with twice the mass of Enteromorpha clathrate was added and mixed thoroughly. Then the mixture was heated to $800^{\circ} \mathrm{C}$ at the rate of $5{ }^{\circ} \mathrm{C} / \mathrm{min}$ and kept for $60 \mathrm{~min}$. The sample was pickled with $2 \mathrm{~mol} / \mathrm{L}$ hydrochloric acid for $24 \mathrm{~h}$. Then the sample was repeatedly washed with deionized water until the $\mathrm{pH}$ of the filtrate reached neutral to remove the inorganic salts and impurities from the sample. After that, the washed samples were put into a drying oven at $105^{\circ} \mathrm{C}$ for $24 \mathrm{~h}$. The samples were denoted as $\mathrm{T}-\mathrm{W}-\mathrm{A}$, where $\mathrm{T}$ represents Enteromorpha clathrate, $\mathrm{W}$ represents the additional nitrogen source $(\mathrm{S}, \mathrm{N})$, and $\mathrm{A}$ represents the activator $\left(\mathrm{KOH}, \mathrm{ZnCl}_{2}\right)$.

\subsubsection{Material Characterization}

The ultimate analysis was performed on the Elemental Analyzer Vario EL III (Elementar, Germany). The surface morphology of the samples was determined by scanning electron microscopy (SEM, Hitachi, TM3000) using a $5 \mathrm{kV}$ accelerating voltageand low vacuum.

The investigation of $\mathrm{N}_{2}$ adsorption/desorption isotherms was performed with a Quantachrome Autosorb IQ analyzer. Using the as-obtained results, the specific surface area of the samples was calculated by the BET equation, and the total pore volume was estimated by the adsorption capacity of nitrogen at the relative 
pressure $\mathrm{P} / \mathrm{P}_{0}=0.99$. The measurement range of relative pressure was $0.01 \sim 0.995$, whereas the measurement range of aperture was $2.0-300.0 \mathrm{~nm}$. The sample was dried at $105^{\circ} \mathrm{C}$ for $24 \mathrm{~h}$ before measurement, and the excess gas impurities were removed at $200^{\circ} \mathrm{C}$.

X-ray diffractometry (XRD) was used to determine the structural characteristics and crystal structure of the samples. An XRD-6100 diffractometer (Shimadzu, Japan) was used for this purpose. The analysis used $\mathrm{Cu} \mathrm{K} \alpha$ radiation at $30 \mathrm{kV}$. The scanning range was performed between $10-80^{\circ}$ ( $2 \theta$ angles), with a scan rate of $5 \%$ min.

To study the surface functional groups of the carbonaceous materials, the samples were analyzed by Fourier transform infrared (FTIR) using a Nicolet 6700 infrared spectrometer (Thermo, USA). Firstly, the raw material and potassium bromide were mixed, ground at a ratio of 1:100, and pressed into pellets. Subsequently, the sample data was collected under the scanning number of 32 and the infrared spectrum of $4000-400 \mathrm{~cm}^{-1}$.

X-ray photoelectron spectroscopy (XPS) is used to analyze the presence of different elements in the sample. A Thermo Scientific Nexsa XPS analyzer was used for this purpose. The analysis used Mono $\mathrm{AlKa}$ radiation at $12 \mathrm{kV}$. The scanning energy was $1486.6 \mathrm{eV}$.

The Raman analysis was performed on the Laser Raman Spectrometer DXR (ThermoFisher, USA). Raman spectrum is a kind of scattering spectrum which is one of the important test methods to study crystal and molecular structures.

\subsubsection{Electrochemical Measurements}

The preparation method of the working electrode was performed using the following sequence: firstly, the prepared carbon material was fully mixed with carbon black, and polytetrafluoroethylene in the ratio of 8:1:1, and then 1-2 drops of 1-methyl-2-pyrrolidone were added, and thoroughly mixed in a mortar. The mixture (about $2.5-5 \mathrm{mg}$ ) was evenly coated on nickel foam with an area of $1 \mathrm{~cm} \times 1 \mathrm{~cm}$. The asprepared working electrode was dried in a drying oven at $105^{\circ} \mathrm{C}$ for $24 \mathrm{~h}$.

The three-electrode electrochemical setup was used, with an auxiliary electrode of Pt electrode, and a reference electrode of $\mathrm{Hg} / \mathrm{HgO}$ electrode. The electrolyte was a $6 \mathrm{~mol} / \mathrm{L} \mathrm{KOH}$ solution. Cyclic voltammetry (CV), galvanostatic charge/discharge (GCD) and cyclic charge-discharge tests were performed using an electrochemical workstation (Chi 660e, Shanghai Chenhua, China). The applied scanning speed were $2,5,10,20,50$, and $100 \mathrm{mV} / \mathrm{s}$, whereas the current densities of GCD were $0.5,1$, 2 , and $3 \mathrm{~A} / \mathrm{g}$, respectively. The current density of cyclic charge-discharge tests was $5 \mathrm{~A} / \mathrm{g}$ and the cycle index was 1000. The specific capacitance of carbon material was calculated according to formula (1)

$C=\frac{I \times \Delta t}{m \times \Delta V}$

where I (A) and $\Delta \mathrm{V}(\mathrm{V})$ represent the change of current and voltage during charging and discharging, respectively. Moreover, $\Delta \mathrm{t}(\mathrm{s})$ represents the discharge time, whereas $\mathrm{m}(\mathrm{g})$ represents the mass of the loaded mixture on the working electrode.

\section{Results and Discussions}

\subsection{The Ultimate Analysis of Carbon Materials}

Tab. 1 shows the results of the elemental analysis of carbon materials with different nitrogen sources and activators. As shown in the table, the content of nitrogen and hydrogen in Enteromorpha clathrate-no additional nitrogen source- $\mathrm{ZnCl}_{2}$ (TZ) was higher than that in Enteromorpha clathrate-no additional nitrogen source-KOH (TK), while the content of carbon in TZ was lower than that in the TK sample. The content of nitrogen in carbon materials was increased by the addition of nitrogen sources. The nitrogen 
contents of Enteromorpha clathrate-urea- KOH (TNK), Enteromorpha clathrate-melamine- KOH (TSK), Enteromorpha clathrate-urea- $\mathrm{ZnCl}_{2}$ (TNZ) and Enteromorpha clathrate-melamine- $\mathrm{ZnCl}_{2}$ (TSZ) were $4.86 \%, 6.18 \%, 12.11 \%$ and $14.76 \%$, respectively. Using the same activator, the nitrogen content of carbon materials was higher in the case of melamine than that in urea. Moreover, using the same nitrogen source, the nitrogen content of carbon materials with $\mathrm{ZnCl}_{2}$ as the activator was generally much higher than that of $\mathrm{KOH}$. Nitrogen atoms have unique electronegativity and atomic radius. Pyridine-N and graphite- $\mathrm{N}$ were formed after nitrogen doping into the carbon matrix, thus, providing active sites for redox reactions [18,35]. With the addition of a nitrogen source, the content of carbon decreased significantly while hydrogen content increased.

Table 1: Ultimate analysis of six carbon materials

\begin{tabular}{llll}
\hline Samples & $\mathrm{N}(\%)$ & $\mathrm{C}(\%)$ & $\mathrm{H}(\%)$ \\
\hline TK & 1.46 & 55.11 & 0.50 \\
TSZ & 14.76 & 33.05 & 1.74 \\
TSK & 6.18 & 20.60 & 0.95 \\
TNZ & 12.11 & 47.98 & 1.56 \\
TNK & 4.86 & 12.37 & 0.89 \\
TZ & 3.75 & 46.17 & 1.80 \\
\hline
\end{tabular}

\subsection{SEM Analysis}

Fig. 1 shows the SEM micrographs of as-obtained carbonaceous materials. The results showed that all samples had rough surface, abundant pore structures and folded structures. This kind of porous structure can reduce the transport resistance of reactants, and the fold structure can carry more active sites. Comparing Figs. 1a and 1f, it was observed that $\mathrm{ZnCl}_{2}$ had more accentuated porous structure. On the other hand, comparing Figs. 1a-1c and 1f, it was found that adding urea as a nitrogen source induced the appearance of a mutually supporting network structure. This structure was conducive for further increasing the specific surface area of samples and maintaining the stability of these constructions. These morphologies could occur due to the decomposition of urea into $\mathrm{NH}_{3}$ at high temperatures. $\mathrm{NH}_{3}$ could severely etch the carbon skeleton and promote large number of pores, forming nitrogen-doped carbon materials with the desired/high specific surface area and developed mesoporous structure [36]. Comparing Figs. 1a and $1 \mathrm{~d}-1 \mathrm{f}$, it was found that the addition of melamine as an exogenous nitrogen source increased the particles on the surface of carbon materials, which induced the formation of macropores. On the other hand, abundant folds could improve more active sites. However, some pore structures could be blocked, which is not conducive for the full infiltration of the electrolyte [37] .

\subsection{Porosity Analysis}

The adsorption/desorption isotherms of the samples are shown in Fig. 2. The TK, TNK, and TSK samples showed similar adsorption-desorption isotherms belonging to the third type isotherm with a steep rising point $\left(\mathrm{P} / \mathrm{P}_{0}>0.8\right)$. TNK decreased slowly than TSK and TK near $\mathrm{P}_{0}$, and the hysteresis loop width was the largest at medium pressure, indicating that TNK had a more porous structure [38,39]. On the other hand, TZ, TNZ, and TSZ showed similar adsorption/desorption isotherms, belonging to the fourth type isotherm, with two steep rising points $\left(\mathrm{P} / \mathrm{P}_{0}<0.1, \mathrm{P} / \mathrm{P}_{0}>0.4\right)$. At low and medium relative pressures, the adsorption capacity of TZ was the highest, the adsorption capacity of TNZ was higher than that of 
TSZ. This result indicated that the addition of exogenous nitrogen reduced the mesoporous and microporous structures when $\mathrm{ZnCl}_{2}$ was used as the activator [40]. The as-obtained mesoporous structures could be beneficial to the diffusion and transport of electrolyte ions, which shortened the time to enter into the inner surface of the micropore to form an electric double layer [41]. On the other hand, micropores were favorable for charge accumulation. The pore structure parameters of the samples are shown in Tab. 2. It can be observed that the pore structure parameters of the TZ were much better than those in the TK without nitrogen doping.
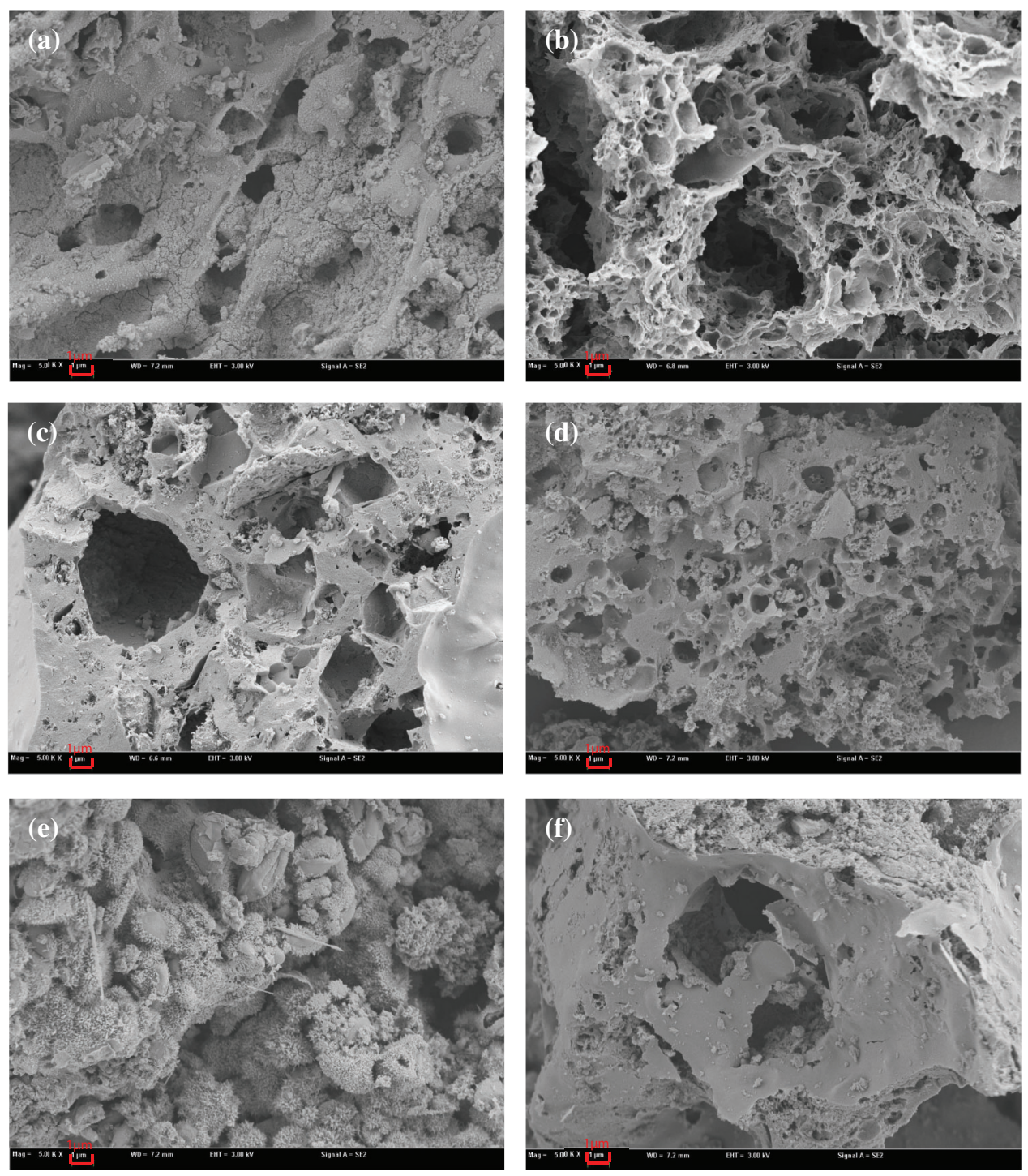

Figure 1: SEM micrographs of different carbonaceous samples: (a) TK (b) TNK (c) TNZ (d) TSK (e) TSZ (f) $\mathrm{TZ}$

When $\mathrm{ZnCl}_{2}$ was used as an activator, the specific surface area and the total pore volume of samples decreased with the addition of exogenous nitrogen. On the other hand, using $\mathrm{KOH}$ as an activator and urea as exogenous nitrogen, the specific surface area and total pore volume of samples increased. The specific surface area and total pore volume of carbonaceous materials with melamine were much lower 
than those without nitrogen. TZ had the highest specific surface area and pore volume of $217.277 \mathrm{~m}^{2} \mathrm{~g}^{-1}$ and $0.327 \mathrm{~cm}^{3} \mathrm{~g}^{-1}$ as given in Tab. 2, respectively.

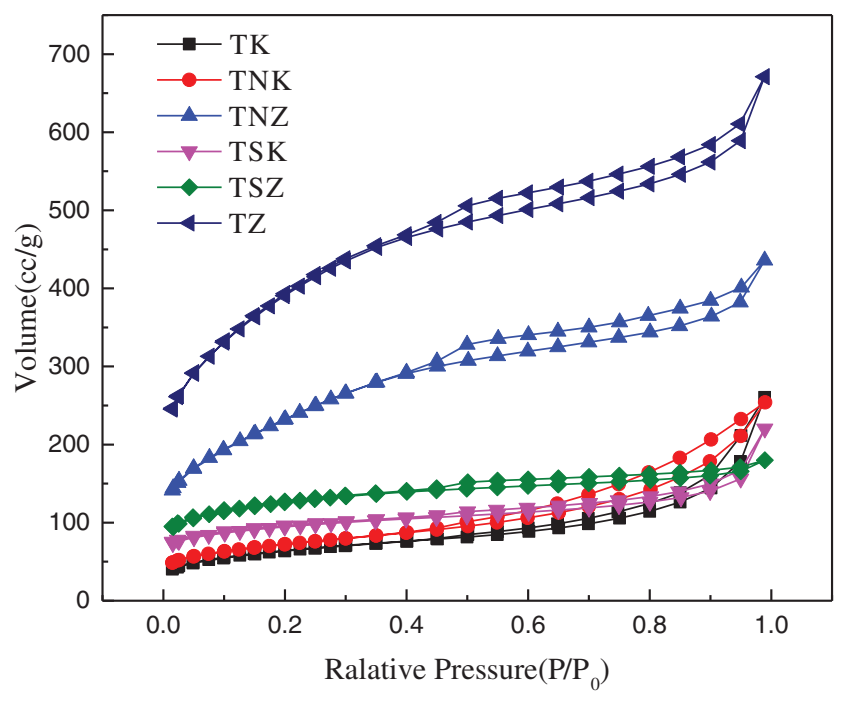

Figure 2: $\mathrm{N}_{2}$ adsorption/desorption isotherms of carbon-based materials

Table 2: Structural parameters of carbon-based materials

\begin{tabular}{llll}
\hline Samples & $\mathrm{S}_{\mathrm{BET}}\left(\mathrm{m}^{2} \mathrm{~g}^{-1}\right)$ & Pore volume $\left(\mathrm{cm}^{3} \mathrm{~g}^{-1}\right)$ & Pore diameter $(\mathrm{nm})$ \\
\hline TK & 97.018 & 0.261 & 3.836 \\
TNK & 144.813 & 0.299 & 3.822 \\
TNZ & 188.896 & 0.263 & 3.830 \\
TSK & 59.233 & 0.125 & 3.835 \\
TSZ & 55.895 & 0.075 & 3.827 \\
TZ & 217.277 & 0.327 & 3.820 \\
\hline
\end{tabular}

\subsection{XRD Analysis}

The structural characteristics of the as-prepared samples were determined by X-ray diffractometry. According to Fig. 3, there was a peak (002) between the ranges of $15-30^{\circ}$ ( $2 \theta$ angles), corresponding to the structure characteristics of carbon materials. The sharp peak mainly corresponded to $\mathrm{SiO}_{2}, \mathrm{CuCl}_{2}$, $\mathrm{KCl}$ and $\mathrm{ZnCl}_{2}$. Alkali and alkaline earth metals $(\mathrm{K}, \mathrm{Ca}, \mathrm{Na}, \mathrm{Mg})$ are the most abundant metal elements in biomass [42]. TNZ and TSZ showed a wide peak between the range of $15-30^{\circ}$ ( $2 \theta$ angles). This diffraction peak belongs to disordered carbon. This could be observed at high temperatures when $\mathrm{Zn}$ turns into $\mathrm{Zn}$ vapor, resulting in large pore structure in carbon materials [43]. From the figure, the six kinds of carbon materials did not show broad peak (100). This result indicated that the carbon material is partially graphitized [36].

\subsection{FTIR Analysis}

Fig. 4 shows the FTIR analysis of nitrogen-rich carbon-based materials. Absorption peaks of $\mathrm{O}-\mathrm{H}, \mathrm{C}=\mathrm{O}$, $\mathrm{C}=\mathrm{H}$, and $\mathrm{C}-\mathrm{H}$ of about $3500,1700,1670$, and $1390 \mathrm{~cm}^{-1}$, respectively, were observed in all six samples. 
Due to the dehydration of $\mathrm{ZnCl}_{2}$, the O-H absorption peaks of TNK and TSK were weak, however, they showed obvious $\mathrm{C}=\mathrm{O}$ absorption peaks [44]. Redox reaction of the carboxyl group can occur in alkaline electrolytes, which can improve the electrochemical performance of carbon materials [4,33]. TNZ and TSZ showed the absorption peak of $\mathrm{C}=\mathrm{N}$ [26]. The following reactions may occur in the electrolytes which can improve the electrochemical performance of carbon materials [13]:

$-\mathrm{CH}=\mathrm{NH}+2 \mathrm{H}_{2} \mathrm{O}+2 \mathrm{e}^{-} \leftrightarrow-\mathrm{CH}-\mathrm{NH}_{2}+2 \mathrm{OH}^{-}$
$-\mathrm{CH}-\mathrm{NHOH}+\mathrm{H}_{2} \mathrm{O}+2 \mathrm{e}^{-} \leftrightarrow-\mathrm{C}-\mathrm{NH}_{2}+2 \mathrm{OH}^{-}$

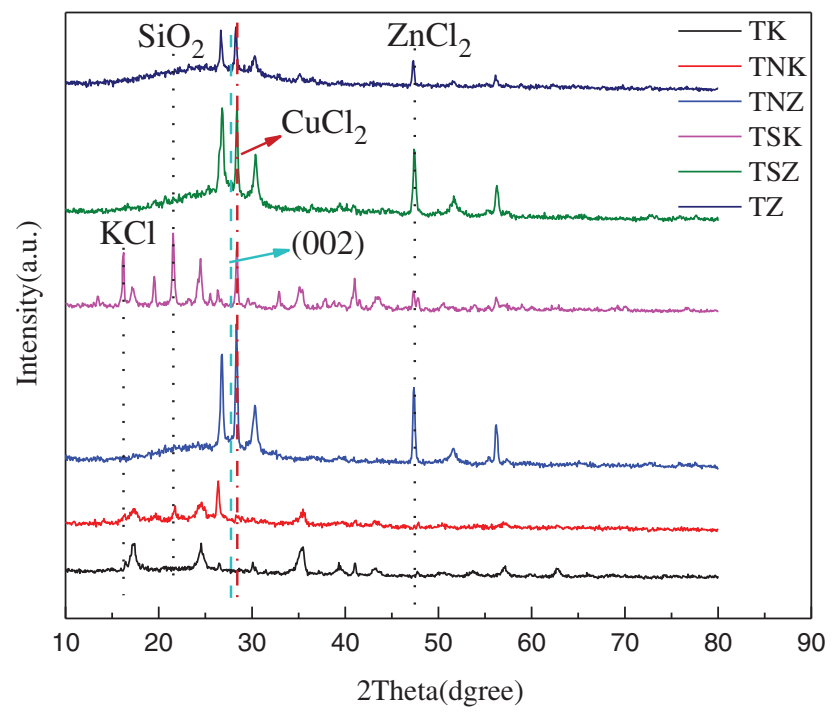

Figure 3: XRD patterns of as-obtained carbonaceous materials

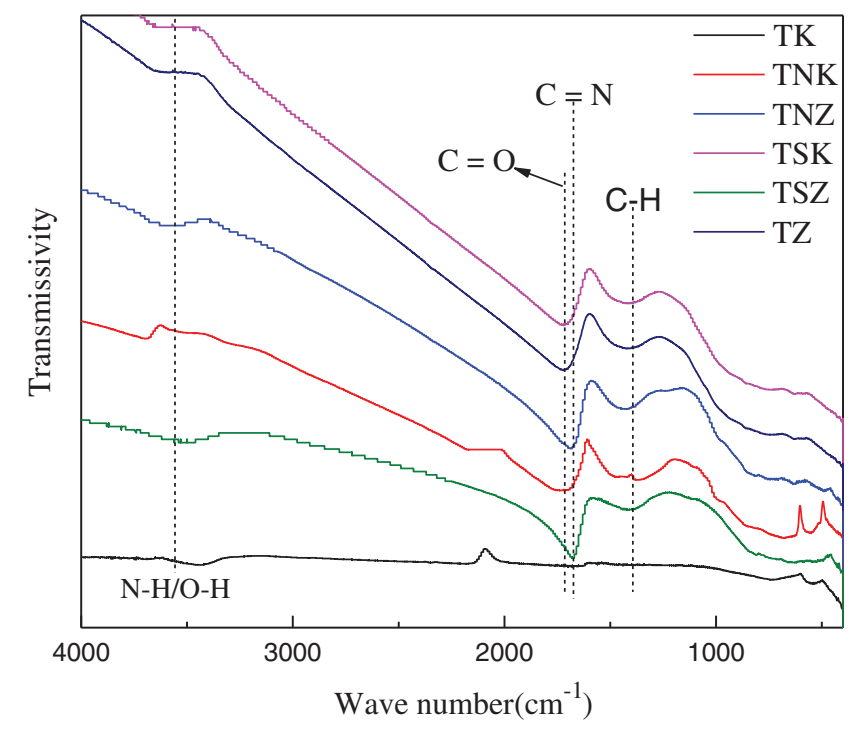

Figure 4: FTIR analysis of carbon-based samples 


\subsection{XPS Analysis}

Fig. 5 shows the full spectrum of the six carbon materials. All samples had obvious $\mathrm{C} 1 \mathrm{~s}$ peak of about $285.08 \mathrm{eV}$, obvious O $1 \mathrm{~s}$ peak of about $532.08 \mathrm{eV}$, and weak N $1 \mathrm{~s}$ peak of about $400.08 \mathrm{eV}$. The XPS N spectrum as displayed in Figs. 6a-6f shows the effects of different activators and exogenous nitrogen on the distribution of nitrogen species. The Binding Energies (BE) of the six samples are $400.4 \mathrm{eV}( \pm 0.1$ $\mathrm{eV}), 398.2 \mathrm{eV}( \pm 0.1 \mathrm{eV}), 401.2 \mathrm{eV}( \pm 0.3 \mathrm{eV})$, and $402.5 \mathrm{eV}( \pm 2 \mathrm{eV})$, corresponding to pyrrole nitrogen, pyridine nitrogen, graphite nitrogen and nitrogen oxide, respectively [45]. Tab. 3 shows the proportion of four nitrogen species in each carbon material. It could be seen from the Tab. 3 that using $\mathrm{KOH}$ as the activator was more conducive for the formation of pyridine nitrogen whereas using $\mathrm{ZnCl}_{2}$ was beneficial for the formation of graphite nitrogen. With the same activator, the content of graphite nitrogen could be reduced while that of pyridine nitrogen could be increased by adding exogenous nitrogen. Pyridine nitrogen could accommodate more electrolyte ions, and had the largest contribution to capacitance in all kinds of electrolytes [21]. There was suitable binding energy between pyrrole nitrogen and electrolyte ions which could improve the capacitance [46]. Graphite nitrogen had a positive charge in the carbon lattice. When it is used as the cathode material, it can bring more positive charges to improve the capacitance [47].

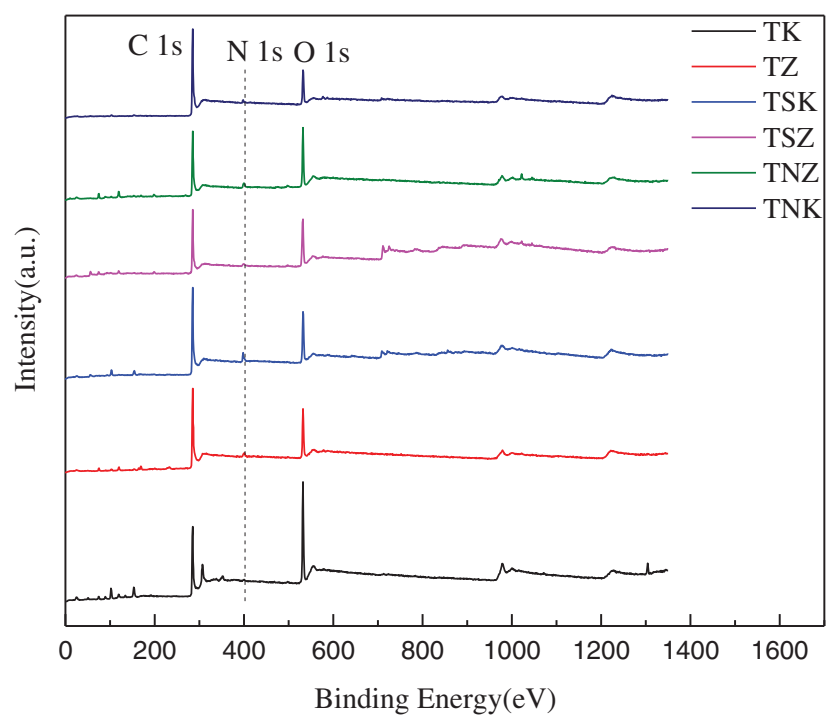

Figure 5: XPS full spectrum of six carbon materials

Among the six carbon materials, TNK and TSZ exhibited the highest specific capacitance. This result may be due to the proportion of pyridine nitrogen in TNK, which could be as high as $70.65 \%$, and could enhance the pseudocapacitance, redox reaction rate and electron transfer rate. The content of nitrogen species in TSZ was similar to that of TK, however, the nitrogen content in TSZ was as high as $14.76 \%$. With the increase of total nitrogen content, the surface active sites of carbon materials increased, thus improving their electrochemical performance [21]. 


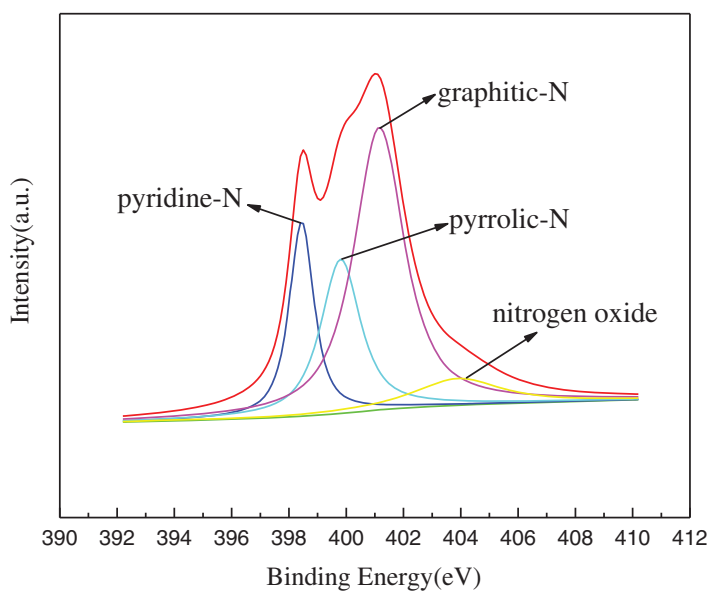

(a)

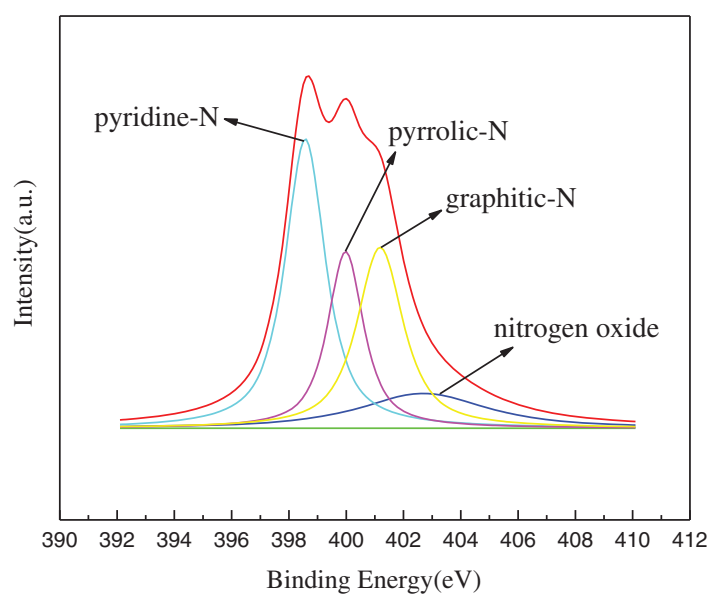

(c)

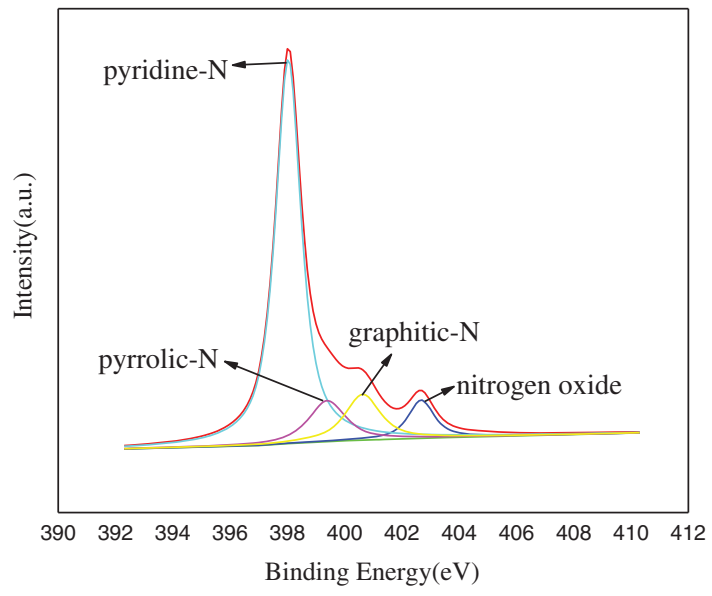

(e)

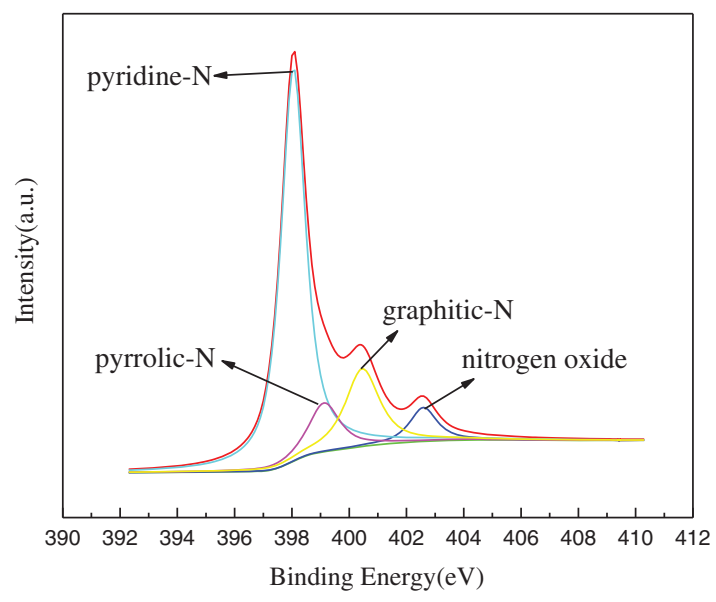

(b)

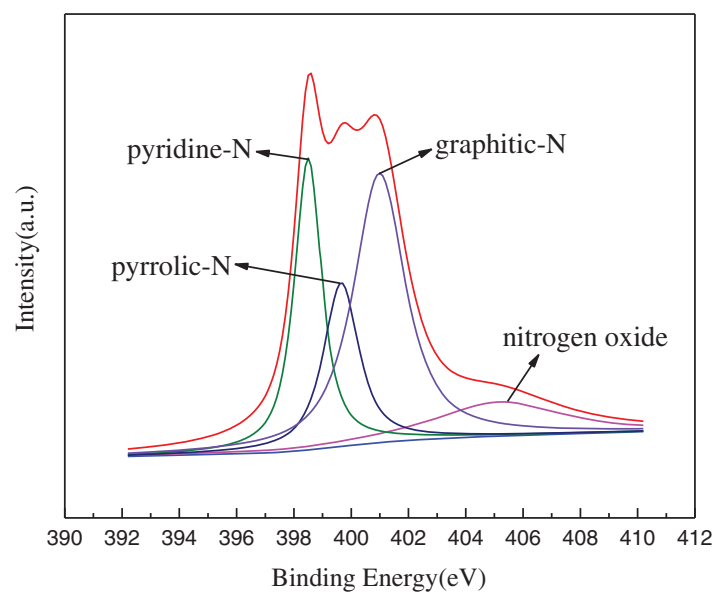

(d)

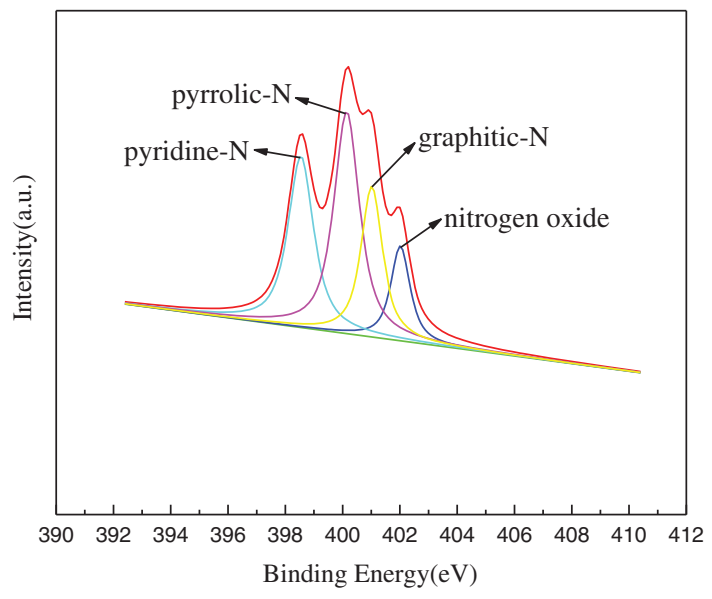

(f)

Figure 6: XPS analysis of carbon-based samples: (a) XPS spectrum of TZ; (b) XPS spectrum of TSK; (c) XPS spectrum of TSZ; (d) XPS spectrum of TNZ; (e) XPS spectrum of TNK; (f) XPS spectrum of TK 
Table 3: Content of nitrogen species in carbon materials

\begin{tabular}{lllll}
\hline Samples & Nitrogen oxide & Pyridine-N & Pyrrolic-N & Graphitic-N \\
\hline TZ & $8.34 \%$ & $17.62 \%$ & $22.31 \%$ & $51.74 \%$ \\
TSK & $6.25 \%$ & $65.35 \%$ & $10.38 \%$ & $18.02 \%$ \\
TSZ & $14.36 \%$ & $37.82 \%$ & $20.64 \%$ & $27.18 \%$ \\
TNZ & $13.43 \%$ & $25.11 \%$ & $18.13 \%$ & $43.34 \%$ \\
TNK & $7.12 \%$ & $70.65 \%$ & $10.70 \%$ & $11.52 \%$ \\
TK & $12.07 \%$ & $28.90 \%$ & $37.57 \%$ & $21.46 \%$ \\
\hline
\end{tabular}

\subsection{Raman Analysis}

Fig. 7 shows the Raman spectra of six groups of samples. All the samples had obvious D and G peaks of about 1350 and $1580 \mathrm{~cm}^{-1}$, which belonged to $\mathrm{SP}^{3}$ hybrid amorphous carbon and $\mathrm{SP}^{2}$ hybrid graphite carbon, respectively. Generally, the disorder degree of carbon materials was expressed by the ratio of D peak to $G$ peak $\left(I_{D} / I_{G}\right)$. The larger the ratio, the higher were the defects on the surface of the materials, and the lower were the regularities [48]. In the six groups of samples, TNK had the smallest $\mathrm{I}_{\mathrm{D}} / \mathrm{I}_{\mathrm{G}}$, which meant that TNK had the least surface defects, the highest regularity, and good conductivity. By comparing TZ with TSZ and TK with TSK, it could be found that adding melamine as exogenous nitrogen could improve the $\mathrm{I}_{\mathrm{D}} / \mathrm{I}_{\mathrm{G}}$ value of carbon materials, increase the surface defects, and decrease the regularity $[49,50]$.

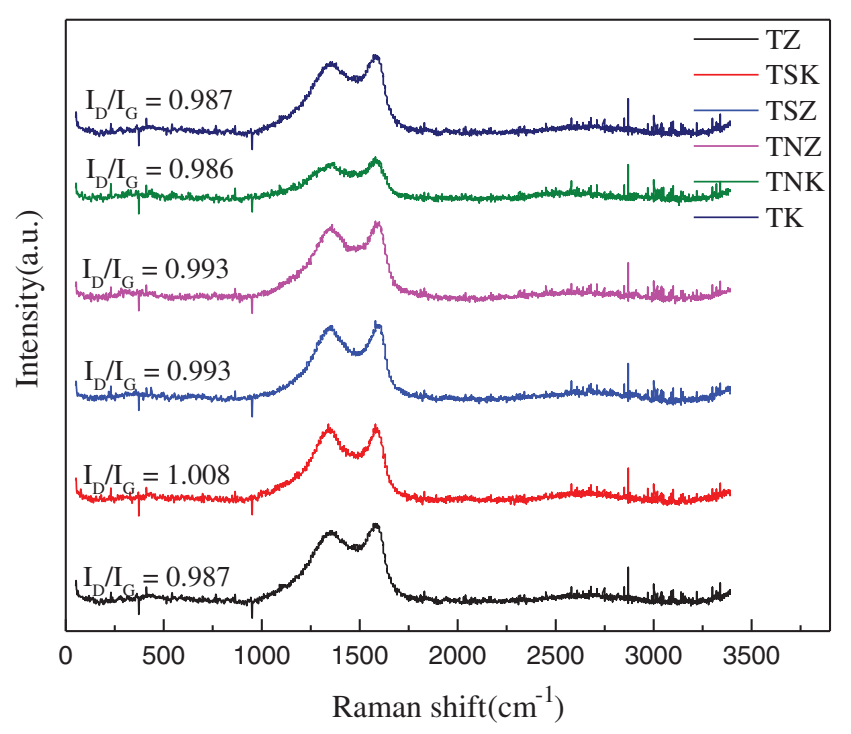

Figure 7: Raman spectra of carbon-based materials 


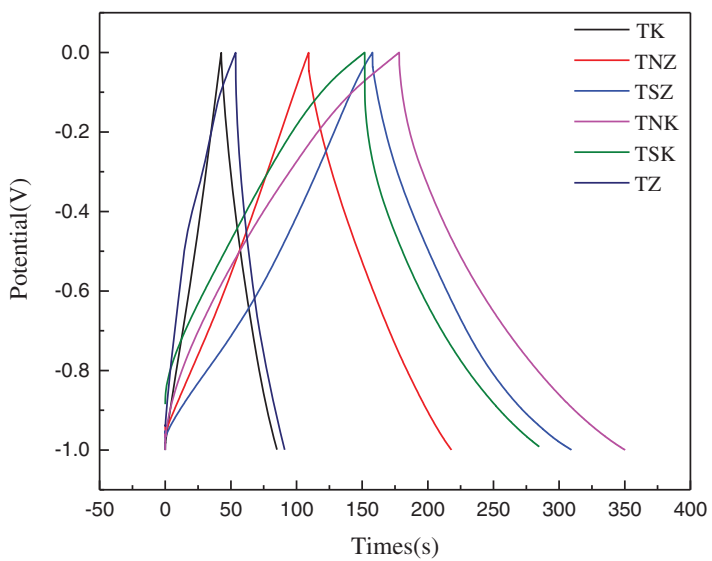

(a)

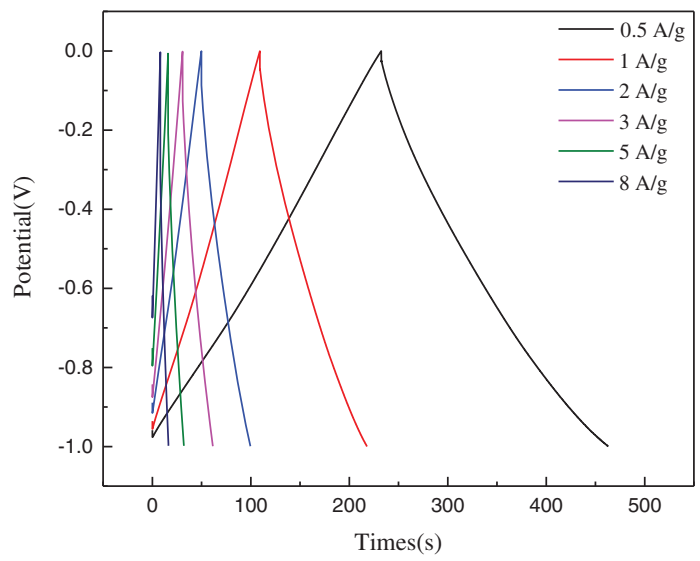

(c)

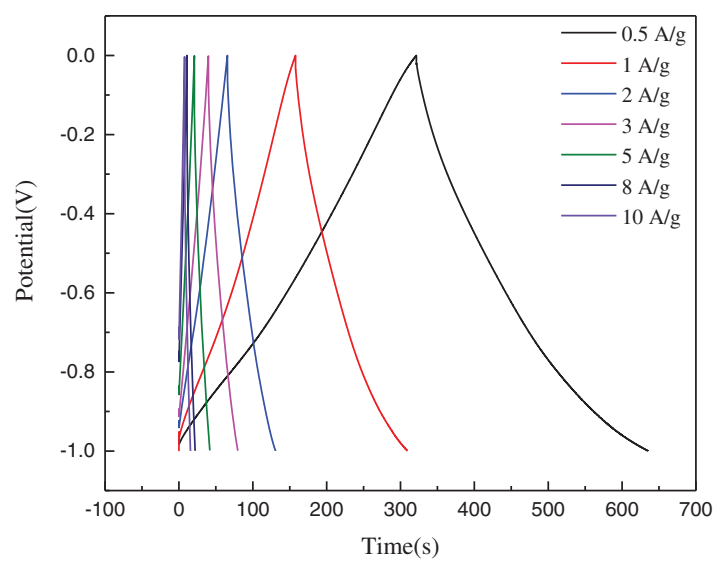

(e)

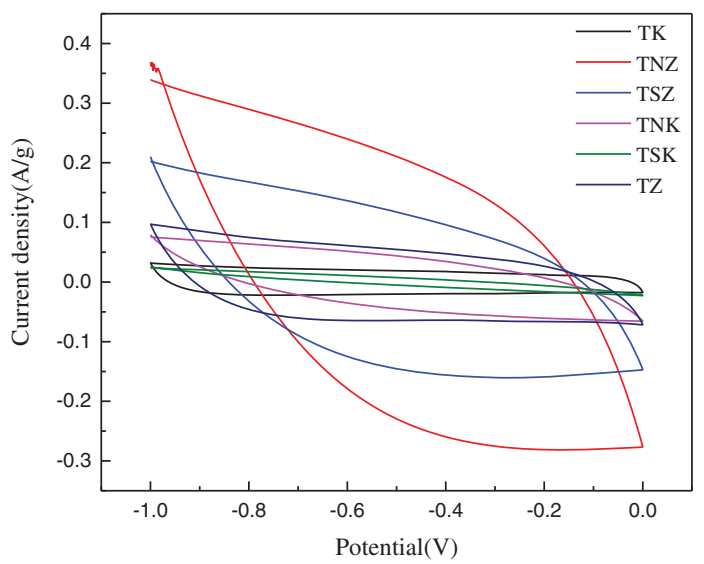

(b)

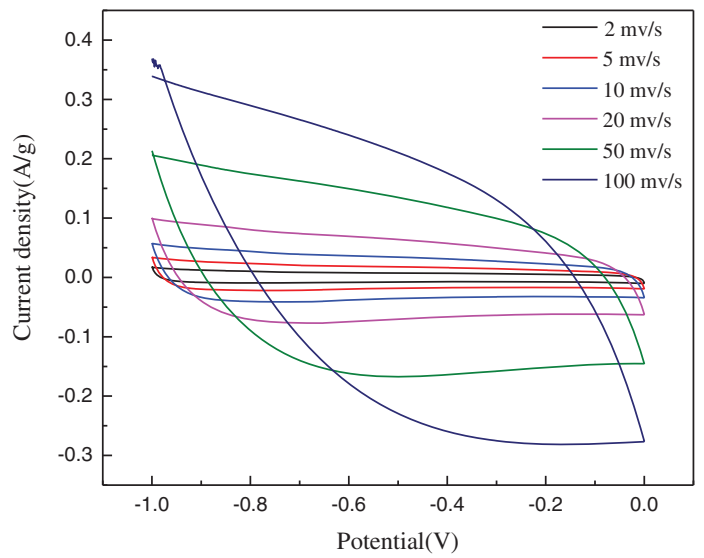

(d)

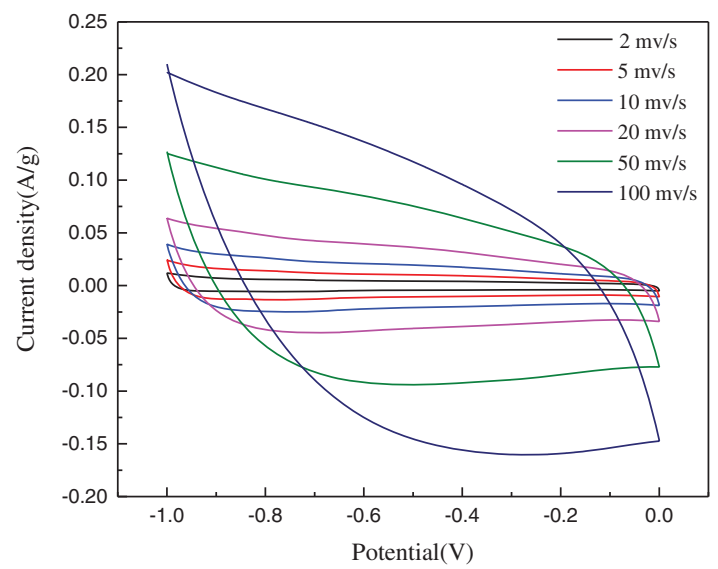

(f)

Figure 8: Continued 


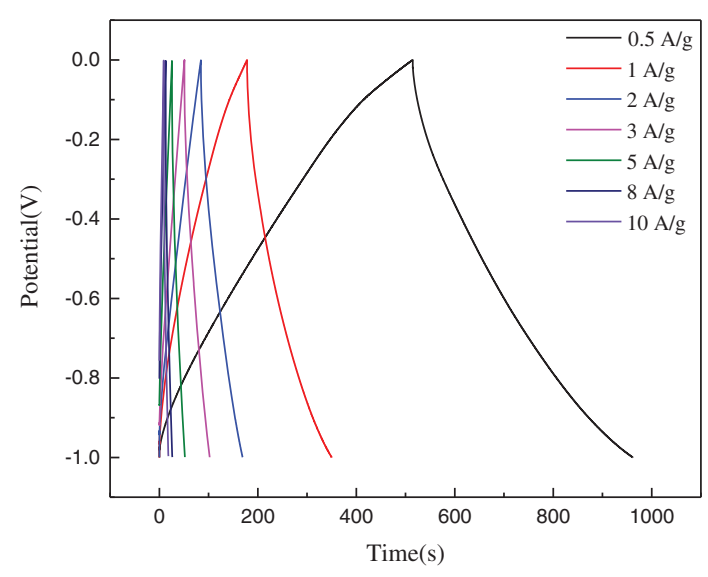

(g)

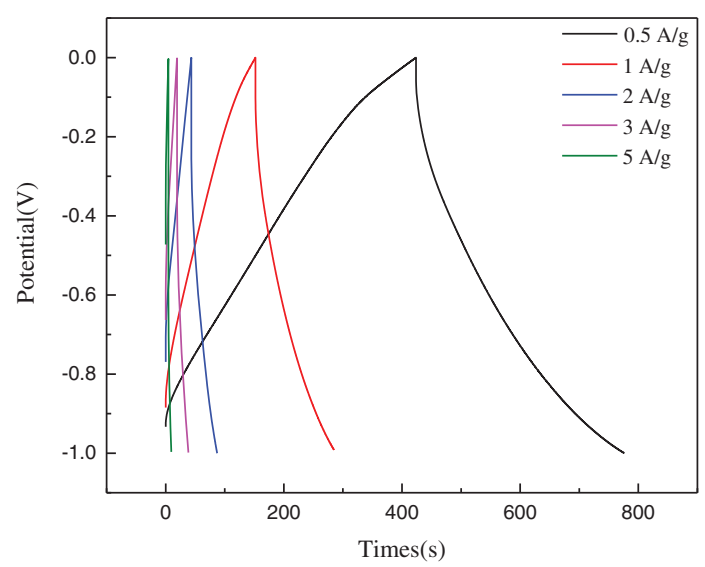

(i)

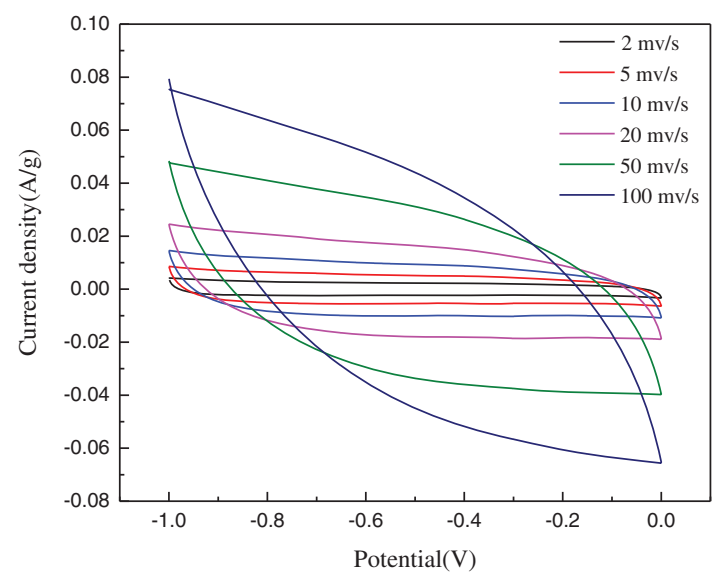

(h)

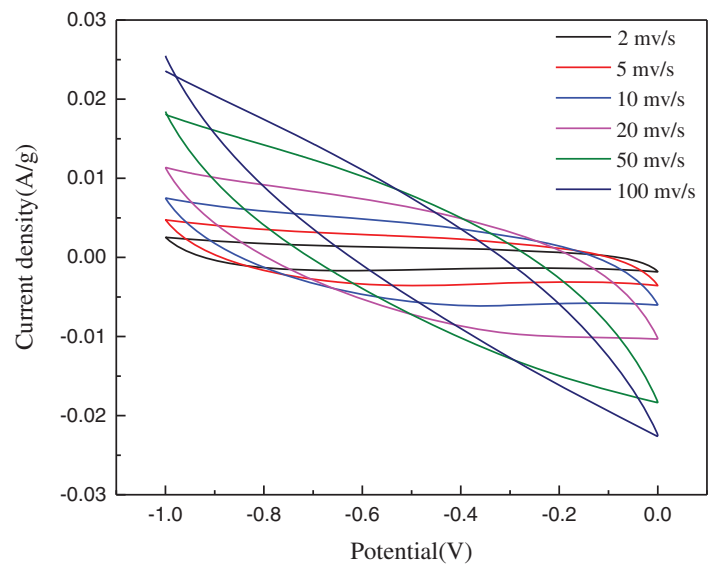

(j)

Figure 8: Electrochemical investigations of carbon-based electrode materials: (a) GCD curves of different samples at $1 \mathrm{~A} / \mathrm{g}$; (b) CV curves of each sample at $100 \mathrm{mV} / \mathrm{s}$; (c) GCD curve of TNZ sample; (d) CV curves of TNZ sample; (e) GCD curve of TSZ sample (f) CV curves of TSZ sample; (g) GCD curve of TNK sample; (h) CV curves of TNK sample; (i) GCD curve of TSK sample; (j) CV curves of TSK sample

\subsection{Electrochemical Performance}

The electrochemical properties of the samples were investigated in $\mathrm{KOH}$ solution $(6 \mathrm{~mol} / \mathrm{L})$ and also, measured by a three-electrode system. The voltage window of the three-electrode test system was $-1 \mathrm{~V}-0$ V. Figs. $8 \mathrm{a}$ and $8 \mathrm{~b}$ show the GCD curves at $1 \mathrm{~A} / \mathrm{g}$ and $\mathrm{CV}$ curves at $100 \mathrm{mV} / \mathrm{s}$, respectively, for the samples. The overall shape of the CV curve was approximately rectangular, which indicated that the material had double-layer capacitance characteristics based on ion adsorption and exchange [15]. However, the shape of the GCD curve tended to be an isosceles triangle, which indicated the excellent redox reversibility of the electrode material [51].

Figs. $8 \mathrm{c}-8 \mathrm{j}$ show the $\mathrm{CV}$ and GCD curves of the four nitrogen-doped carbon materials. The current density was increased from 1 to $10 \mathrm{~A} / \mathrm{g}$, while the scan rates were between $2-100 \mathrm{mV} / \mathrm{s}$. In Fig. $8 \mathrm{~d}$, it was observed that TNZ had the largest area of the CV curve, which indicated that the material had excellent double-layer capacitance. With the increase of scanning speed, there was no obvious deformation of the $\mathrm{CV}$ curves. This observation proved that the material's electrochemical reversibility 
was high. Fig. 8c showed that the GCD curve of TNZ was almost symmetrical, which indicated that the coulomb efficiency of electrode reaction was enhanced.

TNZ had the largest specific surface area between the nitrogen-doped materials, which could induce more electrolyte contacts, thus, accumulating more charges, and subsequently improving the specific capacitance. The electrochemical properties of TZ and TK were similar and inferior. The addition of nitrogen could effectively improve the specific capacitance of carbon materials. TSZ and TNK had larger specific capacitance because of the following reasons. (i) TSZ had the highest nitrogen content. Nitrogen atoms could improve the wettability between carbonaceous materials and electrolytes, provide active sites for a redox reaction, form imine functional groups, and also increase the pseudocapacitance of samples; (ii) TNK showed the large specific surface area and rich mesoporous/microporous structure, which could reduce the resistance of electrolyte transport in electrode, and promote charge accumulation. TNK also showed a pronounced carboxyl absorption peak, which could react with alkaline electrolytes to increase the pseudocapacitance of carbon materials.

It can be seen from Fig. 9 that the specific capacitance of the six carbon materials decrease with the increase of current density. With the increase of current density and the influence of diffusion kinetics, the number of ions adsorbed on the surface of electrode material decreased. The reduction of the number of ions led to the decrease of the specific capacitance [52,53]. However, the specific capacitances of TK and $\mathrm{TZ}$ were less affected by the current density, and the specific capacitance of TSK decayed most sharply with the current density.

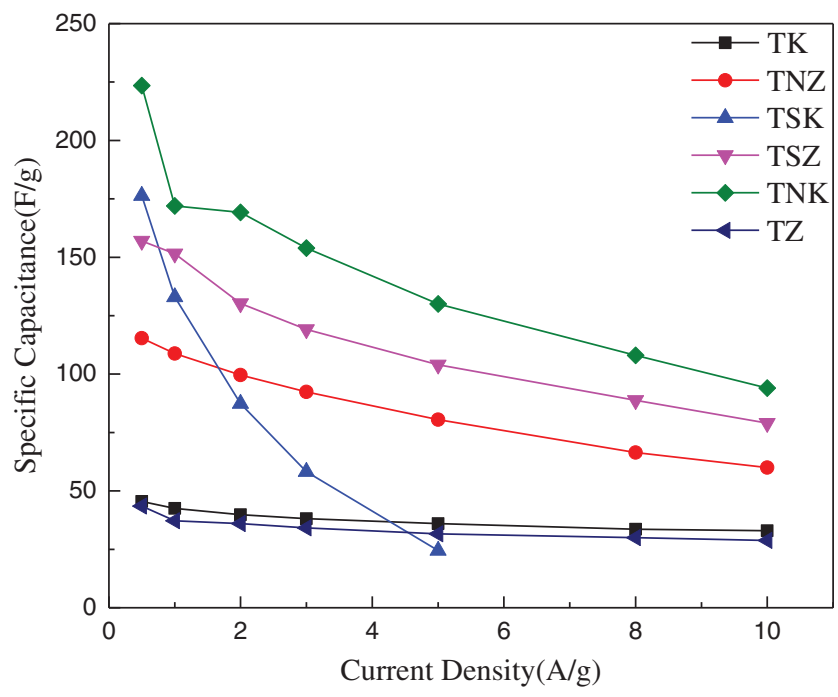

Figure 9: Specific capacitance of carbon materials at different current densities

Fig. 10 shows the change of specific capacitance of the six carbon materials under the current density of $5 \mathrm{~A} / \mathrm{g}$ for 1000 cycles. It can be seen from the figure that the specific capacitance of carbon material changed most drastically in the first 200 times of charge-discharge process. However specific capacitance attenuation was very small after 200 charge-discharge time. After 1000 cycles, the specific capacitances of TSZ, TNK, TZ and TK were $82.6 \%, 78.3 \%, 82.7 \%$ and $65.4 \%$ of the initial specific capacitances, respectively, which indicate that they have good cycle stability. The specific capacitance of TNZ increased gradually in the first 50 cycles, which may be due to the electrolyte entering into the electrode material and the activation of the electrode material. It can be seen from Figs. 9 and 10 that the specific capacitance of TSK 
decreased most drastically in the first 200 cycles. Moreover, its specific capacitance decreased the fastest with the increase of current density. This may be due to the poor stability of the carbon material, and with the increase of cycle times and current density, the ion diffusion resistance of the electrode material also increased [7,54].

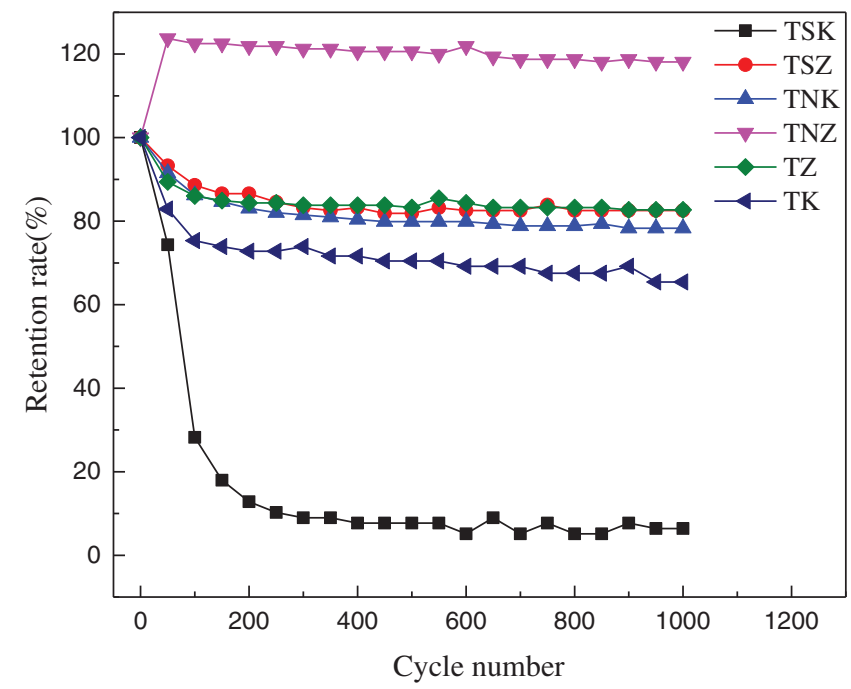

Figure 10: Cycling performance of carbon-based electrode materials

\subsection{Comparison with Other Methods Reported in Literature}

Tab. 4 shows the comparison of the performance of TNK and TSZ, to those of electrode materials prepared by other methods reported in literature. The carbon material from Han et al. (denoted as $\mathrm{H}$ ) had high specific surface area of $1683.42 \mathrm{~m}^{2} \mathrm{~g}^{-1}$, while its specific capacitance and average pore volume were smaller than those of TNK and TSZ [11]. The carbon material from Du et al. (denoted as D) had larger specific capacitance than those of TNK and TSZ, but its specific capacitance was only $37.9 \mathrm{~F} / \mathrm{g}$ [15]. The carbon material from Jiang et al. (denoted as J) had surface area of $317 \mathrm{~m}^{2} \mathrm{~g}^{-1}$, while its specific capacitance was only $115 \mathrm{~F} / \mathrm{g}$. Besides, its $\mathrm{I}_{\mathrm{D}} / \mathrm{I}_{\mathrm{G}}$ was 1.18 , which was higher than those of TNK and TSZ [16].

Table 4: Comparison with other methods reported in literature

\begin{tabular}{llllll}
\hline Sample & $\mathrm{S}_{\mathrm{BET}}\left(\mathrm{m}^{2} \mathrm{~g}^{-1}\right)$ & Pore diameter $(\mathrm{nm})$ & Specific capacitance $(\mathrm{F} / \mathrm{g})$ & Retention rate $(\%)$ & $\mathrm{I}_{\mathrm{D}} / \mathrm{I}_{\mathrm{G}}$ \\
\hline TNK & 144.813 & 3.822 & 172 & 78.3 & 0.986 \\
$\mathrm{TSZ}$ & 55.895 & 3.827 & 151.5 & 82.6 & 0.993 \\
$\mathrm{H}$ & 1683.42 & 2.18 & 138 & 90 & $*$ \\
$\mathrm{D}$ & 1197 & $*$ & 37.9 & 82 & $*$ \\
$\mathrm{~J}$ & 317 & 3.8 & 115 & $*$ & 1.18 \\
\hline
\end{tabular}

Note: *means not mention.

\section{Conclusions}

By comparing the properties of carbonaceous materials obtained from different nitrogen sources and activators, this study gives insight into the preparation of high-performance nitrogen-doped porous carbon 
materials. The results showed that the electrochemical properties of carbon materials improved by adding the appropriate nitrogen sources.

However, the mechanisms of different nitrogen sources to improve the electrochemical properties of carbon materials were different. Urea mainly decomposed into $\mathrm{NH}_{3}$ at high temperature to etch carbon materials, thus, increasing the specific surface area of the samples and improving the double-layer capacitance and the electrochemical performance of carbon materials. Without exogenous nitrogen, the specific surface areas of TK and TZ were 97.018 and $217.277 \mathrm{~m}^{2} \mathrm{~g}^{-1}$, respectively. The specific surface areas of TNK and TNZ were 144.813 and $188.896 \mathrm{~m}^{2} \mathrm{~g}^{-1}$ with urea used as the exogenous nitrogen, while those of TSK and TSZ were only 59.233 and $55.895 \mathrm{~m}^{2} \mathrm{~g}^{-1}$ with melamine used as the exogenous nitrogen.

When melamine was used as exogenous nitrogen, the nitrogen content of carbon materials increased from $1.46 \%$ and $3.75 \%$ to $6.18 \%$ and $14.76 \%$, respectively, while that of urea increased to $4.86 \%$ and $12.11 \%$, respectively. Under the same activator condition, the carbon material with melamine as exogenous nitrogen was about $2 \%$ more than urea. This was because under high temperature, part of nitrogen in urea was discharged in the form of $\mathrm{NH}_{3}$. Melamine could also improve the electrochemical performance of carbon materials by increasing the nitrogen content of carbon materials to form imine functional groups and subsequently improve the pseudocapacitance of carbon materials.

Using the same activator as a decisive parameter, there could be significant differences in the electrochemical performance of carbon materials depending on the source of the exogenous nitrogen. The results showed that the electrochemical performance of carbonaceous materials could significantly improve by both using melamine as a nitrogen source and $\mathrm{ZnCl}_{2}$ as the activator, or urea with $\mathrm{KOH}$. TNK and TSZ exhibited specific capacitances of 172 and $151.5 \mathrm{~F} / \mathrm{g}$, respectively, at $1 \mathrm{~A} / \mathrm{g}$. After 1000 cycles, their specific capacitance retention rate reached $78.3 \%$ and $82.6 \%$, respectively. These results implied that these materials could be used as electrode materials for supercapacitors.

Acknowledgement: Kaihan Xie: Investigation, Writing-Original draft preparation; Yamin Hu: Conceptualization, Data curation; Stephen Afonaa-Mensah: Language and grammar adjustment; Chuan Yuan: Investigation, Supervision; Bin Cao: Data Curation, Supervision; Shuang Wang: Conceptualization, Methodology, Supervision; Qian Wang: Methodology, Supervision.

Funding Statement: This work was supported by the Natural Science Foundation of Jiangsu Province (BK20200894); Key Research and Development Project of Jiangsu Province (BE2019009-4); Key Laboratory of Renewable Energy, Chinese Academy of Science (E029kf0201).

Conflicts of Interest: The authors declare that they have no conflicts of interest to report regarding the present study.

\section{References}

1. Barati, B., Zeng, K., Baeyens, J., Wang, S., Addy, M. et al. (2021). Recent progress in genetically modified microalgae for enhanced carbon dioxide sequestration. Biomass and Bioenergy, 145, 105927. DOI 10.1016/j. biombioe.2020.105927.

2. Elsayed, M., Abomohra, A. E. F., Ai, P., Wang, D., El-Mashad, H. M. et al. (2018). Biorefining of rice straw by sequential fermentation and anaerobic digestion for bioethanol and/or biomethane production: Comparison of structural properties and energy output. Bioresource Technology, 268, 183-189. DOI 10.1016/j. biortech.2018.07.130.

3. Chen, M. Z., Liu, X. Z., Zhang, S. P., Zhang, H. L. (2020). Research and analysis of biomass fuel air calorific value. Energy Research and Utilization, 2020(5), 18-21+35. DOI 10.16404/j.cnki.issn1001-5523.2020.05.001. 
4. Pandolfe, A. G., Hollenkamp, A. F. (2006). Carbon properties and their role in supercapacitors. Journal of Power Sources, 157(1), 11-27. DOI 10.1016/j.jpowsour.2006.02.065.

5. Bhattacharjya, D., Yu, J. S. (2014). Activated carbon made from cow dung as electrode material for electrochemical double layer capacitor. Journal of Power Sources, 262, 224-231. DOI 10.1016/j.jpowsour.2014.03.143.

6. Takeshi, M. (2004). Development and industrialization of electric double-layer capacitors. TANSO, 2004(214), 202-209. DOI 10.7209/tanso.2004.202.

7. Zhu, Y. W., Murali, S., Stoller, M. D., Ganesh, K. J., Cai, W. W. et al. (2011). Carbon-based supercapacitors produced by activation of graphene. Science, 332(6037), 1537-1541. DOI 10.1126/science.1200770.

8. Pell, W. G., Conway, B. E. (2001). Voltammetry at a de levie brush electrode as a model for electrochemical supercapacitor behaviour. Journal of Electroanalytical Chemistry, 500(1-2), 121-133. DOI 10.1016/S00220728(00)00423-X.

9. Wang, H. L., Casalongue, H. S., Liang, Y. Y., Dai, H. J. (2010). Ni(OH) $)_{2}$ nanoplates grown on graphene as advanced electrochemical pseudocapacitor materials. Journal of the American Chemical Society, 132(21), 7472-7477. DOI 10.1021/ja102267j.

10. Qu, D., Shi, H. (1998). Studies of activated carbons used in double-layer capacitors. Journal of Power Sources, 74(1), 99-107. DOI 10.1016/S0378-7753(98)00038-X.

11. Han, J., Chen, S., Rong, C., Chen, L., Zhang, K. (2015). Preparation and properties of corncob based activated carbon materials for supercapacitor. International Journal of Automotive Technology, (9), 16-19. DOI 10.3969/ j.issn.1000-3703.2015.09.005.

12. Armandi, M., Bonelli, B., Geobaldo, F., Garrone, E. (2010). Nanoporous carbon materials obtained by sucrose carbonization in the presence of KOH. Microporous \& Mesoporous Materials, 132(3), 414-420. DOI 10.1016/ j.micromeso.2010.03.021.

13. Wang, Y., Song, Y., Xia, Y. (2016). Electrochemical capacitors: Mechanism, materials, systems, characterization and applications. Chemical Society Reviews, 45(21), 5925-5950. DOI 10.1039/C5CS00580A.

14. Qu, D. (2002). Studies of the activated carbons used in double-layer supercapacitors. Journal of Power Sources, 109(2), 403-411. DOI 10.1016/S0378-7753(02)00108-8.

15. Du, X., Wang, C., Chen, M., Jiao, Y., Wang, J. (2009). Electrochemical performances of nanoparticle $\mathrm{Fe}_{3} \mathrm{O}_{4} /$ Activated carbon supercapacitor using $\mathrm{KOH}$ electrolyte solution. Journal of Physical Chemistry C, 113(6), 2643-2646. DOI 10.1021/jp8088269.

16. Jiang, J., Zhang, L., Wang, X., Holm, N., Rajagopalan, K. et al. (2013). Highly ordered macroporous woody biochar with ultra-high carbon content as supercapacitor electrodes. Electrochimica Acta, 113, 481-489. DOI 10.1016/j.electacta.2013.09.121.

17. Shi, H. (1996). Activated carbons and double layer capacitance. Electrochimica Acta, 41(10), 1633-1639. DOI 10.1016/0013-4686(95)00416-5.

18. Chmiola, J., Largeot, C., Taberna, P. L., Simon, P., Gogotsi, Y. (2008). Desolvation of ions in subnanometer pores and its effect on qucapacitance and double-layer theory. Angewandte Chemie International Edition, 47(18), 33923395. DOI 10.1002/ange.200704894.

19. Gratuito, M. K., Panyathanmapom, T., Chumnanklang, R. A., Sirinuntawittaya, N., Dutta, A. (2008). Production of activated carbon from coconut shell: Optimization using response surface methodology. Bioresource Technology, 99(11), 4887-4895. DOI 10.1016/j.biortech.2007.09.042.

20. Varil, T., Bergna, D., Lahti, R., Romar, H., Hu, T. et al. (2017). Activated carbon production from peat using $\mathrm{ZnCl}_{2}$ : Characterization and applications. BioResources, 12, 8078-8092. DOI 10.15376/biores.12.4.8078-8092.

21. Mao, X., Cao, Z., Yin, Y., Wang, Z. C., Dong, H. Y. et al. (2018). Direct synthesis of nitrogen and phosphorus codoped hierarchical porous carbon networks with biological materials as efficient electrocatalysts for oxygen reduction reaction. International Journal of Hydrogen Energy, 43(22), 10341-10350. DOI 10.1016/j. ijhydene.2018.04.100.

22. Wang, L., Mu, G., Tian, C., Sun, L., Zhou, W. et al. (2013). Porous graphitic carbon nanosheets derived from cornstalk biomass for advanced supercapacitors. ChemSusChem, 6, 880-889. DOI 10.1002/cssc.201200990. 
23. Fuertes, A. B., Sevilla, M. (2015). High-surface area carbons from renewable sources with a bimodal micromesoporosity for high-performance ionic liquid-based supercapacitors. Carbon, 94, 41-52. DOI 10.1016/j. carbon.2015.06.028.

24. Pan, G. X. (2020). Application of MOFs and their composites in lithium ion batteries. Energy Research and Utilization, 2020(2), 22-26. DOI 10.16404/j.cnki.issn1001-5523.2020.02.011.

25. Yang, T., Qian, T., Wang, M., Liu, J., Zhou, J. Q. et al. (2015). A new approach towards the synthesis of nitrogendoped graphene $/ \mathrm{mno}_{2}$ hybrids for ultralong cycle-life lithium ion batteries. Journal of Materials Chemistry A, 3(12), 6291-6296. DOI 10.1039/c4ta07208a.

26. Xu, B., Hou, S., Cao, G., Wu, F., Yang, Y. (2012). Sustainable nitrogen-doped porous carbon with high surface areas prepared from gelatin for supercapacitors. Journal of Materials Chemistry, 22, 19088-19093. DOI $10.1039 / \mathrm{c} 2 \mathrm{jm} 32759 \mathrm{~g}$.

27. Zhou, H., Zhang, J., Amiinu, I. S., Zhang, C. Y., Liu, X. B. et al. (2016). Transforming waste biomass with an intrinsically porous network structure into porous nitrogen-doped graphene for highly efficient oxygen reduction. Physical Chemistry Chemical Physics, 18(15), 10392-10399. DOI 10.1039/c6cp00174b.

28. Zhou, H., Zhang, J., Zhu, J. W., Liu, Z. Y., Zhang, C. T. et al. (2016). A self-template and KOH activation cocoupling strategy to synthesize ultrahigh surface area nitrogen-doped porous graphene for oxygen reduction. RSC Advances, 6(77), 73292-73300. DOI 10.1039/C6RA16703A.

29. Hu, Y. M., Wang, H. W., Lakshmikandan, M., Wang, S., Wang, Q. et al. (2021). Catalytic co-pyrolysis of seaweeds and cellulose using mixed ZSM-5 and MCM-41 for enhanced crude bio-oil production. Journal of Thermal Analysis and Calorimetry, 143, 827-842. DOI 10.1007/s10973-020-09291-w.

30. Lucia, B., Raghu, C., Federico, C., Brunet, C. (2014). The challenge of ecophysiological biodiversity for biotechnological applications of marine microalgae. Marine Drugs, 12(3), 1641-1675. DOI 10.3390/ md12031641.

31. Minowa, T., Yokoyama, S., Kishimoto, M., Okakura, T. (1995). Oil production from algal cells of dunaliella tertiolecta by direct thermochemical liquefaction. Fuel, 74(12), 1735-1738. DOI 10.1016/0016-2361(95)80001-X.

32. Lakshmikandan, M., Murugesan, A. G., Wang, S., Abomohra, A. E. F., Anjelin Jovita, P. et al. (2020). Sustainable biomass production under $\mathrm{CO}_{2}$ conditions and effective wet microalgae lipid extraction for biodiesel production. Journal of Cleaner Production, 247, 119398. DOI 10.1016/j.jclepro.2019.119398.

33. Zhao, S. Y., Wang, C., Bai, B., Jin, H., Wei, W. W. (2022). Study on the polystyrene plastic degradation in upercritical water $/ \mathrm{CO}_{2}$ mixed environment and carbon fixation of polystyrene plastic in $\mathrm{CO}_{2}$ environment. Journal of Hazardous Materials, 421, 126763. DOI 10.1016/j.jhazmat.2021.126763.

34. Xu, S. N., Cao, B., Bernard Uzoejinwa, B., Alepu Odey, E., Wang, S. et al. (2020). Synergistic effects of catalytic co-pyrolysis of macroalgae with waste plastics. Process Safety and Environmental Protection, 137, 34-48. DOI 10.1016/j.psep.2020.02.001.

35. Gu, D., Zhou, Y., Ma, R., Wang, F. F., Liu, Q. et al. (2017). Facile synthesis of N-doped graphene-like carbon nanoflakes as efficient and stable electrocatalysts for the oxygen reduction reaction. Nano-Micro Letters, 10(2), 29. DOI 10.1007/s40820-017-0181-1.

36. Chen, W., Yang, H., Chen, Y., Chen, X., Fang, Y. et al. (2016). Biomass pyrolysis for nitrogen-containing liquid chemicals and nitrogen-doped carbon materials. Journal of Analytical and Applied Pyrolysis, 120, 186-193. DOI 10.1016/j.jaap.2016.05.004.

37. Li, Q., Jiang, R., Dou, Y., Wu, Z. X., Huang, T. et al. (2011). Synthesis of mesoporous carbon spheres with a hierarchical pore structure for the electrochemical double-layer capacitor. Carbon, 49(4), 1248-1257. DOI 10.1016/j.carbon.2010.11.043.

38. Rojas, F., Kornhauser, I., Felipe, C., Esparza, J. M., Cordero, S. et al. (2002). Capillary condensation in heterogeneous mesoporous networks consisting of variable connectivity and pore-size correlation. Physical Chemistry Chemical Physics, 4(11), 2346-2355. DOI 10.1039/b108785a.

39. Yao, M., Zhao, X., Jin, L., Zhao, F. Y., Zhang, J. X. et al. (2017). High energy density asymmetric supercapacitors based on MOF-derived nanoporous carbon/manganese dioxide hybrids. Chemical Engineering Journal, 322, 582 589. DOI 10.1016/j.cej.2017.04.075. 
40. Sevilla, M., Mokaya, R. (2014). Energy storage applications of activated carbons: Supercapacitors and hydrogen storage. Energy \& Environmental Science, 7(4), 1250-1280. DOI 10.1039/c3ee43525c.

41. Chen, D., Zhou, H., Li, H., Chen, J., Li, S. X. et al. (2017). Self-template synthesis of biomass-derived 3D hierarchical N-doped porous carbon for simultaneous determination of dihydroxybenzene isomers. Scientific Reports, 7(1), 14985. DOI 10.1038/s41598-017-15129-7.

42. Hirohata, O., Wakabayashi, T., Tasaka, K., Fushimi, C., Furusawa, T. et al. (2014). Release behavior of tar and alkali and alkaline earth metals during biomass steam gasification. Energy \& Fuels, 22(6), 4235-4239. DOI $10.1021 / \mathrm{ef} 800390 \mathrm{n}$.

43. Hwang, H. S. O., Cho, T. S., Choi, I. G., Choi, J. W. (2013). Fast pyrolysis of potassium impregnated poplar wood and characterization of its influence on the formation as well as properties of pyrolytic products. Bioresour Technology, 150, 359-366. DOI 10.1016/j.biortech.2013.09.132.

44. Marrakchi, F., Zafar, F. F., Wei, M. M., Wang, S. (2021). Cross-linked $\mathrm{FeCl}_{3}$-activated seaweed carbon/MCM-41/ alginate hydrogel composite for effective biosorption of bisphenol a plasticizer and basic dye from aqueous solution. Bioresource Technology, 331, 125046. DOI 10.1016/j.biortech.2021.125046.

45. Ranganathan, K., Morais, A., Nongwe, I., Longo, C., Nogueira, A. et al. (2016). Study of photoelectrochemical water splitting using composite films based on $\mathrm{TiO}_{2}$ nanoparticles and nitrogen or boron doped hollow carbon spheres as photoanodes. Journal of Molecular Catalysis A: Chemical, 422, 165-174. DOI 10.1016/j. molcata.2015.10.024.

46. Jeong, H. M., Lee, J. W., Shin, W. H., Choi, Y. J., Shin, H. J. et al. (2011). Nitrogen-doped graphene for highperformance ultracapacitors and the importance of nitrogen-doped sites at basal planes. Nano Letters, 11(6), 2472-2478. DOI 10.1021/nl2009058.

47. Zhu, Z. H., Hatori, H., Wang, S. B., Lu, G. Q. (2005). Insights into hydrogen atom adsorption on and the electrochemical properties of nitrogen-substituted carbon materials. The Journal of Physical Chemistry B, 109(35), 16744-16752. DOI 10.1021/jp051787o.

48. Kudin, K. N., Ozbas, B., Schniepp, H. C., Prud'homme, R. K., Aksay, I. A. et al. (2008). Raman spectra of graphite oxide and functionalized graphene sheets. Nano Letters, 8(1), 36-41. DOI 10.1021/n1071822y.

49. Liu, J., Li, W., Duan, L., Li, X., Ji, L. et al. (2015). A graphene-like oxygenated carbon nitride material for improved cycle-life lithium/sulfur batteries. Nano Letters, 15, 5137-5142. DOI 10.1021/acs.nanolett.5b01919.

50. Yang, L., Chen, C., Xu, G. B., Yang, L. W. (2016). Macroscopic three-dimensional tetrapod-separated graphenelike oxygenated N-doped carbon nanosheets architecture for use in supercapacitors. Journal of Materials Chemistry A, 4, 9900-9909. DOI 10.1039/C6TA04062D.

51. Du, W., Wang, X., Sun, X., Zhan, J., Zhang, H. D. et al. (2018). Nitrogen-doped hierarchical porous carbon using biomass-derived activated carbon/carbonized polyaniline composites for supercapacitor electrodes. Journal of Electroanal Chemistry, 827, 213-220. DOI 10.1016/j.jelechem.2018.09.031.

52. Yang, C. M., Kim, Y. J., Endo, M., Kanoh, H., Yudasaka, M. et al. (2007). Nanowindow-regulated specific capacitance of supercapacitor electrodes of single-wall carbon nanohorns. Journal of the American Chemical Society, 129(1), 20-21. DOI 10.1021/ja065501k.

53. Wang, S. R., Dai, G., Ru, B., Zhao, Y., Wang, X. L. et al. (2017). Influence of torrefaction on the characteristics and pyrolysis behavior of cellulose. Energy, 120, 864-871. DOI 10.1016/j.energy.2016.11.135.

54. Kozawa, A., Yeager, J. F. (1965). The cathodic reduction mechanism of electrolytic manganese dioxide in alkaline electrolyte. Journal of the Electrochemical Society, 112(10), 959-963. DOI 10.1149/1.2423350. 